\title{
QUEEN'S
UNIVERSITY
BELFAST
}

\section{Silicon, the silver bullet for mitigating biotic and abiotic stress, and improving grain quality, in rice?}

Meharg, C., \& Meharg, A. A. (2015). Silicon, the silver bullet for mitigating biotic and abiotic stress, and improving grain quality, in rice? Environmental and Experimental Botany, 120, 8-17.

https://doi.org/10.1016/j.envexpbot.2015.07.001

\section{Published in:}

Environmental and Experimental Botany

\section{Document Version:}

Peer reviewed version

Queen's University Belfast - Research Portal:

Link to publication record in Queen's University Belfast Research Portal

\section{Publisher rights}

(c) 2015, Elsevier. Licensed under the Creative Commons Attribution-NonCommercial-NoDerivatives 4.0 International

$\mathrm{http}: / /$ creativecommons.org/licenses/by-nc-nd/4.0/ which permits distribution and reproduction for non-commercial purposes, provided the author and source are cited.

\section{General rights}

Copyright for the publications made accessible via the Queen's University Belfast Research Portal is retained by the author(s) and / or other copyright owners and it is a condition of accessing these publications that users recognise and abide by the legal requirements associated with these rights.

\section{Take down policy}

The Research Portal is Queen's institutional repository that provides access to Queen's research output. Every effort has been made to ensure that content in the Research Portal does not infringe any person's rights, or applicable UK laws. If you discover content in the Research Portal that you believe breaches copyright or violates any law, please contact openaccess@qub.ac.uk. 


\section{Accepted Manuscript}

Title: Silicon, the silver bullet for mitigating biotic and abiotic stress, and improving grain quality, in rice?

Author: Caroline Meharg Andrew A. Meharg

PII: $\quad$ S0098-8472(15)30001-0

DOI: $\quad$ http://dx.doi.org/doi:10.1016/j.envexpbot.2015.07.001

Reference: $\quad$ EEB 2960

To appear in: $\quad$ Environmental and Experimental Botany

Received date: $\quad$ 15-6-2015

Revised date: 26-6-2015

Accepted date: $\quad$ 1-7-2015

Please cite this article as: Meharg, Caroline, Meharg, Andrew A., Silicon, the silver bullet for mitigating biotic and abiotic stress, and improving grain quality, in rice?.Environmental and Experimental Botany http://dx.doi.org/10.1016/j.envexpbot.2015.07.001

This is a PDF file of an unedited manuscript that has been accepted for publication. As a service to our customers we are providing this early version of the manuscript. The manuscript will undergo copyediting, typesetting, and review of the resulting proof before it is published in its final form. Please note that during the production process errors may be discovered which could affect the content, and all legal disclaimers that apply to the journal pertain. 
Silicon, the silver bullet for mitigating biotic and abiotic stress, and improving grain quality, in rice?

\section{Caroline Meharg* and Andrew A. Meharg*}

Institute for Global Food Security, Queen's University Belfast, David Keir

Building, Malone Road, BT9 5BN, Northern Ireland, UK.

*corresponding authors

Caroline Meharg:- caroline.meharg@qub.ac.uk;

Andrew A. Meharg:- aa.meharg@qub.ac.uk

Highlights

\section{?}

Ms. Ref. No.: EEB-D-15-00390

Title: Silicon, the silver bullet for mitigating biotic and abiotic stress, and improving grain quality, in rice?

C. Meharg \& A.A. Meharg

Environmental and Experimental Botany

- Si nutrition is central mitigating abiotic and biotic stress in rice

- Structural Si maintains yield through shoot strength and defends the plant from insect attack

- Structural Si protects against, UV, water-stress, $\mathrm{Na}, \mathrm{Fe}, \mathrm{Mn}$ and Al toxicity 
and lodging

- Si competes with As for uptake and Cd is bound to Si both in cell walls and phytoliths Abstract

- Recycling straw phytolith Si is central to sustainable rice farming

Adequate silicon fertilization greatly boosts rice yield and mitigates biotic and abiotic stress, and improves grain quality through lowering the content of cadmium and inorganic arsenic. This review on silicon dynamics in rice considers recent advances in our understanding of the role of silicon in rice, and the challenges of maintaining adequate silicon fertility within rice paddy systems. Silicon is increasingly considered as an element required for optimal plant performance, particularly in rice. Plants can survive with very low silicon under laboratory/glasshouse conditions, but this is highly artificial and, thus, silicon can be considered as essential for proper plant function in its environment. Silicon is incorporated into structural components of rice cell walls were it increases cell and tissue rigidity in the plant. Structural silicon provides physical protection to plants against microbial infection and insect attack as well as reducing the quality of the tissue to the predating organisms. The abiotic benefits are due to silicon's effect on overall organ strength. This helps protect against lodging, drought stress, high temperature (through efficient maintenance of transpiration), and photosynthesis by protecting against high UV. Furthermore, silicon also protects the plant from saline stress and against a range of toxic metal stresses (arsenic, cadmium, chromium, copper, nickel and zinc). Added to this, silicon application decreases grain concentrations of various human carcinogens, in particular arsenic, antimony and cadmium. As rice is efficient at stripping bioavailable silicon from the soil, recycling of silicon rich 
rice straw biomass or addition of inorganic silicon fertilizer, primarily obtained from iron and steel slag, needs careful management. Silicon in the soil may be lost if the silicon-cycle, traditionally achieved via composting of rice straw and returning it to the land, is being broken. As composting of rice straw and incorporation of composted or non-composted straw back to land are resource intensive activities, these activities are declining due to population shifts from the countryside to cities. Processes that accelerate rice straw composting, therefore, need to be identified to aid more efficient use of this resource. In addition, rice genetics may help address declining available silicon in paddy soils: for example by selecting for characteristics during breeding that lead to an increased ability of roots to access recalcitrant silicon sources from soil and/or via selection for traits that aid the maintenance of a high silicon status in shoots. Recent advances in understanding the genetic regulation of silicon uptake and transport by rice plants will aid these goals.

\section{Introduction:}

Rice can be considered as a silicon accumulator and can have shoot silicon concentrations above $10 \%$ of shoot dry weight (Yamamoto et al., 2012), with typical ranges from low to high being 1.7 to $>3.4 \%$ (Korndorfer et al., 2001). Other members of the Poaceae share this characteristic (Epstein, 1999; Kido et al., 2015; Ma and Takahashi, 2002; Van Bockhaven et al., 2013), but silicon in rice is the most studied because of the economic importance of rice. Rice has specific mechanisms for assimilating silicon from soil as soluble silicic acid, and for 
unloading silicic acid into the xylem, through the aquaglyceroporins lsi1 and lsi2 (i.e. Ma et al., 2006, 2007a). Grasses, in general, seem to utilize silicon in their tissue for defense against biotic and abiotic stresses such as herbivory, leaf microbial pathogen resistance, lodging, salinity, high light intensity, toxic metal stress and drought tolerance (Goto et al., 2003; Kim et al., 2014; Khattab et al., 2014; Ma and Takahashi, 2002; Van Bockhaven et al., 2013). Plants fertilized with silicon, tend to have higher yields than non-fertilized plants. In fact, silicon fertilization has been shown to increase the number of grains per panicle by circa. 25-100\% (Ma and Takahashi, 2002; Zhang et al., 2013a). This can be attributed to the fact that silicon fertilization leads to better structural support and enhanced biomass and, consequently, higher yield bearing capacity, as well as increased resistance against various biotic and abiotic stresses that would otherwise cause yield decline.

Evidence, to date, suggests that silicon does not seem to be directly involved in regulation of cell functions besides it's direct role in plant structural components and cell wall chemistry. Furthermore, silicon appears to interact with defense associated signaling pathways and silicon status seems to regulate a range of physiological activities (Ye et al., 2013; Van Bockhaven et al., 2013). Silicon appears to be fundamental to regulating grain nutrition by playing an important role with respect to assimilation of the problematic toxins arsenic, antimony and cadmium in rice (Liu et al., 2014b; Li et al., 2009).

This review aims to give an overview of the current state of knowledge of silicon in rice considering: soil-plant biogeochemistry; plants genetics involved in 
silicon accumulation, transport and deposition in tissues; the role of silicon in maintaining yield by counteracting biotic and abiotic stress; and how silicon impacts on grain quality. The review, furthermore, provides an overview of topics that require further investigation as it appears that silicon nutrition of paddy soils is declining.

\section{Silicon soil-plant biogeochemical cycle}

\subsection{Silicon soil chemistry}

Total silicon is high in soils as it is the second most abundant element in the earth's crust (Sommer et al., 2006). Soils contain $>50 \% \mathrm{SiO}_{2}$ (Ma and Takahashi, 2002) , predominantly in the form of silicates (aluminum, calcium, iron etc.), quartz, biogenic $\mathrm{SiO}_{2}$ (phytoliths and diatoms) and silica gel (polymerized silicic acid). Soil silicon concentrations range between 1-45\% dependent on soil type (Sommer et al., 2006), and soil mineral composition is often the major determinant in silicon availability to the plants (Haynes, 2014). Solid phase $\mathrm{SiO}_{2}$ is in equilibrium with soluble silicic acid in the soil solution, and it is silicic acid that is the plant available form of silicon (Ma and Takahashi, 2002; Marschner, 2012). Rice has a high demand for silicon, with straw having 4-20\% $\mathrm{SiO}_{2}$. Consequently, for every $100 \mathrm{~kg}$ of brown rice produced, approximatly $20 \mathrm{~kg}$ of $\mathrm{SiO}_{2}$ is being removed from the soil (Ma and Takahashi 2002).

Silicic acid soil chemistry is complex, regulated by soil $\mathrm{pH}$ affecting precipitation and polymerization of plant available silicic acid, with root uptake being greater at lower pH due to higher soil solution concentrations (Tavakkoli et al., 2011). Soil solution silicon ranges between 3-40 mg/L, averaging $\sim 20 \mathrm{mg} / \mathrm{L}$ (Marschner, 2012). Higher concentrations, $>56 \mathrm{mg} / \mathrm{L}$ silicon, are associated with 
supersaturation or partial polymerization (Marschner, 2012). Anaerobism associated with paddy soils drives silicic acid mobilization, probably through dissolution of silicon associated with Fe(III) that is converted to Fe(II) under reduced conditions (Ma and Takahashi, 2002). Silicic acid's pH dependency means that silicon deficiencies are most notable at higher $\mathrm{pHs}>7$ (Korndorfer et al., 2001; Liang et al., 1994). Plant available silicon is also low in soils high in sesquioxides such as highly weathered tropical soils where anion absorption is dominant (Marschner, 2012). Phytolithic biogenic silica dissolves more rapidly to silicic acid compared to other forms of soil silica, and is the dominant source of silicon to rice in paddy environments (Desplanques et al., 2006).

\subsection{Paddy soil silicon cycle}

Inputs of silicon into paddy soils include silica mineral fertilizers, silica mineral particles deposited during alluvial floods, atmospheric inputs as silica and silicic acid, as well as silicic acid irrigation water inputs (Figure 1). Outputs are primarily leaching to groundwater, surface water run-off and removal of straw. Recycling of silicon is through direct reincorporation of straw, reincorporation after composting or reincorporation as manure after use as animal feed. Phytoliths account for $90 \%$ of rice straw silicon (Ma and Takahashi, 2002). As phytoliths' dissolve relatively rapidily to silicic acid recycling of that straw back into soil is a key part of the paddy system silicon soil fertility. This was demonstared by seasonal soluble silicon concentrations in paddy soil systems rising in winter after rice straw incorporation due to the dissolution of straw derived phytoliths (Seyfferth et al., 2013). While phytoliths are mainly noncrystalline silicon-dioxide, they can also contain aluminum, iron and occluded 
carbon (Li, et al. 2014). Evidence suggests that phytoliths with higher aluminum and iron contents break down faster in soils. Research also shows that these high aluminum and iron containing phytoliths are more prevalent in shoots compared to stems, and that the content of phytoliths differs between cultivars (Li et al., 2014).

\subsection{Atmospheric and irrigation water inputs}

Sommer et al. (2006) reviewed the literature on silicon dynamics in terrestrial ecosystems and found that atmospheric inputs from rainwater were small, but solid deposition as dust could be significant in arid climates, while leaching could be an import route for silicon losses from soils. In general, atmospheric and irrigation water inputs supply only $1-10 \%$ of silicon above-ground off-take by rice (Desplanques et al., 2006). While irrigation water inputs tend to be low, when silicic acid in the irrigation water is elevated crop uptake increases (Haynes, 2014). Furthermore, Ma and Takahashi (2002) found that rice straw silicon content was strongly correlated with that in irrigation water concentration: $\mathrm{SiO}_{2}$ content of shoot was $\sim 8 \%$ at $10 \mathrm{mg} / \mathrm{kg}$ in irrigation water, rising to $18 \%$ at concentrations above $30 \mathrm{mg} / \mathrm{kg}$ in the water.

\subsection{Inorganic silicon fertilization}

The main inorganic sources of silicon fertilizers are slags (Haynes, 2014). Metalliferous ores (chromium, iron, manganese and nickel) are heated with limestone and after metal extraction this leaves a calcium silicate waste, slag (Ma and Takahashi, 2002). The main components of slag besides calcium silicate are aluminum, iron and magnesium and traces of chromium, manganese and nickel. 
Slag from iron and steel manufacture that contain primarily calcium silicate, can be used as a silicon fertilizer for rice, and as a liming agent, provided that a high proportion of the silicon is bioavailable, and that the slag is low in potentially toxic metals (Ma and Takahashi, 2002; Ning et al., 2014). To be used as a fertilizer in Japan slag must have $>20 \%$ soluble $\mathrm{SiO}_{2}$ (reduced to $10 \%$ in 1887) and $>35 \%$ alkali component and $<0.4 \%$ nickel and $4 \%$ chromium (Ma and Takahashi, 2002).

Other sources of silicon include Wollastonite, which is a naturally occurring calcium inosilicate $\left(\mathrm{CaSiO}_{3}\right)$ mineral deposit. Wollastonite may also contain small amounts of iron, magnesium, and manganese. Fused magnesium phosphate, formed by heating rock phosphate with serpentinite, is rich in calcium, magnesium, phosphorus and silicon. Potassium silicate, a waste product from coal station fly ash, where the ash is mixed with either potassium carbonate, or potassium hydroxide and magnesium hydroxide and calcined at $900^{\circ} \mathrm{C}$, is high in aluminum, iron, magnesium and potassium, along with silicon. Porous hydrate calcium silicate (tobamolite), produced from quick lime, quartz and cement, reacted at $180^{\circ} \mathrm{C}$ under 10 atm pressure, can also be used as a fertilizer. Industrially produced silica gel is mainly used for nursery applications where there is a need to avoid alkalization. Comparing 12 sources of silicon fertilizer, Pereira et al. (2004) identified that phosphate slag was most effective, followed by Wollastonite and electrical furnace silicates.

\subsection{Straw recycling of silicon}


It was estimated that off-take of silicon by a rice crop was $270 \mathrm{~kg} / \mathrm{ha} /$ year

(Desplanques et al., 2006). If this straw incorporated silicon is not recycled back into the paddy ecosystem, it is a serious loss with major implications for rice fertility. Ma and Takahashi (2002) estimated that, in Japan, historically the application of composted rice straw to the field was equivalent to adding between 300-1000 kg/ha/year $\mathrm{SiO}_{2}$ and, therefore, provided an important buffer against silicon depletion in paddy soil. When rice straw is composted and added to paddy soil, $70 \%$ of the compost added silicon is taken up by rice (Ma and Takahashi, 2002). In a French study conducted by Desplanques et al. (2006), paddy fields without replenishment through fertilization were shown to be depleted in silicon at a rate of $\sim 150 \mathrm{~kg} / \mathrm{ha}$ /year. They found, alarmingly, natural silicon reserves in the soil were estimated to provide for only 5 years. These studies illustrates that continuous input of silicon, either through straw recycling or as mineral fertilizer, is essential to ensure long-term productivity of paddy soils. Maintaining adequate silicon fertility was traditionally achieved via addition of rice straw compost (organic silicon fertilization) or, more recently, inorganic forms of silica fertilization in form of industrially produced slag. In Japan, in the 1950s, composting practice was replaced with silicon fertilization through iron and steel slag, with slag eventually displacing compost in importance, but with the actual rate of silicon fertilization from both sources decreasing dramatically between the 1950s and the year 2000, dropping from over $600 \mathrm{~kg} / \mathrm{ha} /$ year to less than $200 \mathrm{~kg} / \mathrm{ha} /$ year $\mathrm{CaSiO}_{2}$.

Silicon fertilization decreases the nutrient content of rice straw on a unit biomass basis, for calcium, iron, magnesium, manganese, nitrogen and 
phosphorus, often dramatically, (Ma and Takahashi, 2002). Furthermore, the higher the silicon in the rice straw, the more difficult it will be to degrade and compost. This poses a paradox for silicon recycling as the most beneficial straws, i.e. those highest in silicon, are the most difficult to degrade and recycle. The high silicon content of rice straw, compared to other crop straws, makes it more poorly digestible to livestock (Song et al., 2014). However, if manures produced from livestock, that have rice straw as a component of their diet, is incorporated into the compost/soil, the available silicon in soil increases, doubling from 130 to $270 \mathrm{mg} / \mathrm{kg}$ after 10 years in one Chinese example (Song et al., 2014). Besides composting of rice straw, rice husks are also a rich source of silicon and if burnt or carbonized husk is, therefore, also a good silicon fertilizer (Ma and Takahashi, 2002). As well, biochars prepared from rice straw, apart from having a range of beneficial properties generally associated with biochars, could also be employed as a slow release soluble silicon fertilizer (Xiao et al., 2014).

\section{Silicon accumulation, transport and deposition in rice tissues}

\subsection{Silicon uptake and transport}

Plant roots assimilate silicon through aquaglyceroporins (Meharg and Jardine, 2003). The mechanism behind this assimilation is known to involve two genes: lsi1 (Ma et al., 2006) and lsi2 (Ma et al., 2007). Lsi1 is a silicic influx channel, loading silicon into cells and located on the distal cell wall membranes, while lsi2 is a silicon effluxer, situated in the proximal cell wall, unloading silicic acid towards and into the xylem. Lsi1 is primarily located in the basal zones of roots rather than at root tips (Yamaji and Ma. 2007). When the regulation of silicon uptake was studied in contrasting cultivars, a high silicon accumulator and a low 
silicon accumulator, these plants were shown to differ in a number of important attributes (Ma et al., 2007b). While the $\mathrm{K}_{\mathrm{m}}$ for silicon uptake was similar in both plants, the high silicon accumulator had a higher $\mathrm{V}_{\max }$, and this taken along with higher lsi1 and lsi2 expression levels, suggested that it had a higher density of silicon transporters in its roots. Another study, again comparing cultivars that contrasted in their shoot silicon levels, also found that the cultivar that accumulated more silicon appeared to do this through a higher $\mathrm{V}_{\max }(\mathrm{Wu}$ et al., 2006).

Silicon is exported from the root to the shoot and unloaded into stems and leaves. A silicic acid transporter lsi6 was found to be responsible for redirection of silicon at stem nodes (Yamaji and Ma, 2009; Yamaji et al., 2008). Knockout of lsi6 decreased silicon in panicles and increased silicon in flag leaves, showing its physiological role in silicon distribution in the plant. Lsi6 is primarily located in xylem transfer cells at the outer boundary of the enlarged vascular bundles (Yamaji and Ma, 2009).

\subsection{Silicon deposition in tissues}

Silicon is deposited in leaf blades, epidermal and vascular stem tissue, leaf sheath and hull (Ma and Takahashi, 2002), with silicon fertilization leading directly to enhanced thickness in the silicon levels of leaves (Ning et al., 2014).

Silicon in rice is preferentially deposited in epidermal cell walls, were it polymerizes to form silicon-cuticle double layers (Kido et al., 2015). In the leaves of rice, silicon is deposited in "dumbbell" type structures that increase in size as the plant leaf matures, preceded by lignification (Zhang et al., 2013a). Silicon 
deposits in the lumen of the cells through needle-like silica structures, molding the inner cell walls (Zhang et al., 2013a).

The similarity between rice's silicon requirement and that of the Equisetums (Horsetails) lead to a hypothesis that a beta-d-glucan $(1 ; 3,1 ; 4)$ was common between the two and that this glucan may have a key role in silicon-cell wall chemistry Kido et al., 2015). In rice $(1 ; 3,1 ; 4)$ beta-d-glucan knockouts, silicon distribution in leaves was altered and reduced the mechanical properties of the leaf blades (Kido et al., 2015). Increased silicon nutritional content of leaves induced lignin production, oxidative cross-linking in cell walls and phytoalexin production (Sun et al., 2010). When rice cells grown in suspension-culture were fractionated, it was found that silicon was primarily associated, through covalent crosslinking, with hemicelluloses and, thereby, improved the mechanical properties of cells (He et al., 2015a). Lsi1 and lsi2 knockdown resulted in higher lignin accumulation in cell walls to counteract the low silicon structural content in these mutants (Suzuki et al., 2012). In plants starved of silicon, under hydroponic conditions, the leaf blades visibly drooped compared to those supplanted with silicic acid (1.5 mM) (Yamamoto et al., 2012). In the starved plants, sugars, cellulose and lignin content increased, compensating for the lack of silicon with respect to structural integrity.

The structural deposition of germanic acid, a silicic acid analogue, introduced into phloem through a cut leaf, furthermore, illustrates where silicon is deposited in the developing seed (Carey et al., 2012). Germanium is distributed throughout the husk, and husk hairs, achieves high rachilla concentrations, and is 
localized in the ovular vacuolar trace of the edible grain, as is the silicic acid analogue arsenite (Carey et al., 2012). The rice influx transporter has been shown to have a direct role in selenite, another silicic acid analogue (Zhao et al., 2010). Selenite is the dominant form of selenium in soil solution, transported into roots, with lsi1 knockout mutants having significantly reduced selenite accumulation (Zhao et al., 2010). Antimonite is also a silicic acid analogue and, consequently, also assimilated through silicic acid uptake pathways in rice (Huang et al., 2012, Tripathi et al. 2013).

Fleck et al. (2011) studied the role of silicon in root formation and function and found that silicon nutrition increased suberization of the exodermis and lignification of the sclerenchyma, as well as reduced the zone of radial oxygen loss by roots. This study also showed that genes involved in suberin and lignin formation were differentially regulated by silicon nutrition.

\section{The role of silicon in maintaining yield by counteracting stress}

Increased silicon content of leaves enhances their physical resistance as shown by the increased force required by a needle to penetrate the sheath (Schurt et al., 2012) and the enhanced structural rigidity of leaf blades (Yamamoto et al., 2012). Silicon tends to have positive influences in mitigating a range of biotic and abiotic stresses, and in increasing yield. High-yield rice cultivars are dependent on high mechanical strength of their stems (Liang et al., 2013). Comparing lsi1 knockdown mutants known to have significantly reduced selenite accumulation (Zhao et al., 2010) and wild-type rice, under silicon stressed and silicon replete conditions, it was observed that silicon improved harvest index in parallel with 
nitrogen use efficiency and with concurrent alterations of amino acid pools (Detmann et al., 2012).

\subsection{Biotic stress mitigation}

A link of enhanced silicon content to increased defense against pathogens that are dependent on penetrating or consuming rice leaves was established as early as 1917, when it was found that rice with higher silicon content, had lower infection rates of blast (Ma and Takahashi, 2002). Early Japanese research also linked cultivar silicon content to blast resistance, and silicon fertilization to blast and brown spot mitigation. Susceptibility of rice to a range of diseases was identified to be related to genetic variability in silicon content, and to silicon deficiency in the plants. Disease amelioration was again achieved by silicon fertilization, with silicon fertilization also enhancing yield (Datnoff et al., 1992; Deren et al., 1994). Lower rates of infection due to increased physical strength of leafs in response to increased level of silicon will, most certainly, also indirectly affect molecular defense associated signaling responses, as these plants experience reduced levels of stress. While effects of silicon, leading to increased biotic stress resistance, via provision of increased leaf strength, cannot be disputed, it is harder to establish whether silicon also has a direct role in molecular defense associated signaling pathways. This would have to be independent of silicon's role in providing increased physical protection to the leaf tissue. Various studies aimed to further dissect the role of silicon in abiotic stress resistance including the direct impact on molecular defense, independent of silicon's structural role in in the plant (Van Bockhaven et al., 2013). 
Sheath blight, Rhizoctonia solani was decreased in two rice cultivars grown hydropically with 2 mM Si compared to no silicon (Schurt et al., 2014). Other studies into the effects of silicon fertilization and infection rates by sheath blight found that enhanced silicon in the shoot protected both a sensitive and insensitive cultivar from this fungus (Zhang et al., 2013 b). It was hypothesized that silicon may exert this defensive action through interaction with phenolics production, but this was only found to be the case in the sensitive cultivar. A study on two rice cultivars grown hydroponically and fertilized with and without silicic acid found that enhanced silicon content of leaves decreased the damage done by leaf sheaf blight, but this did not appear to be through alteration of the sugar or lignin content of the leaves (Schurt et al., 2013).

Fungal brown spot (Bipolaris oryzae) resistance of rice was improved through slag based silicon fertilization, and resistance was thought to be due to observed structural changes in leaves, with enhanced thickness of the silicon layer in mesophyll cells, and through enhanced cytoplasmic silicon concentrations (Ning et al., 2014). Increased brown spot resistance in response to silicon fertilization was observed to be less in a lsi1 knockout mutant compared to its wild-type counterpart cultivar Oochikara (Dallagnol et al., 2011, Dallagonol et al., 2013, Dallagnol et al., 2014). Silicon fertilization (2mM in hydroponics) reduced infection by $81 \%$ in wild type and $50 \%$ in the mutant (Dallagnol et al., 2011). These benefits of silicon, in protecting against B. oryzae, as measured by leaf sugar content and photosynthetic rate after infection, were identified to be leaf silicon concentration dose dependent (Dallagonol et al., 2013). While high leaf silicon resulted in increase soluble sugar concentration, and to decreasing brown 
spot severity, they did so in independent ways (Dallagonol et al., 2013). In another study the relationship between brown spot sensitivity and leaf silicon was linear and negative across eight rice genotypes in soil grown plants fertilized with silicon (Prabhu et al., 2012). While foliar application of silicon can decrease brown spot, it was not as effective as root-supplied silicon (Rezende et al., 2009). A study on silicon induced rice resistance to brown spot fungus Cachliobolus miyabeanus (the sexual stage of B. oryzae), identified decreased infection to be due to silicon induced regulation of ethylene pathways, apparently through blocking fungal derived ethylene (Van Bockhaven et al., 2015).

Fungal rice blast (Magnaporthe oryzae) resistance was enhanced by silicon fertilization (Abed-Ashtiani et al., 2012; Liu et al., 2014a), with lsi1 deficient mutants found to be more susceptible to blast than their wild-type counterpart (Nakata et al., 2008). Sun et al. (2010) attributes silicon induced resistance to blast to be due to physical changes in cell walls, lignification and oxidative crosslinking. A transcriptional expression study found that silicon affected the interaction between rice and rice-blast fungus at the molecular level (Brunings et al., 2009). In two near isogenic lines, with differential blast resistance, silicon fertilization in nutrient solution was considerably increased in both genotypes (Cai et al., 2008). This was not due to alteration in lignin or defense enzyme function on silicon fertilization per se, but because the silicon and lignin content of shoots increased in response to blast inoculation in both isogenic lines. The authors concluded that silicon acted through physical defense, primarily the deposition of silicon in leaf epidermal cells. Hayaska et al. (2008) also suggested 
that the protection silicon affords to rice blast fungus is protection against its penetration into leaf tissue.

Screening found that rice varieties high in shoot silicon have enhanced resistance to rice leaf folder, Cnaphalocrocis medinalis Guenee, while silicon soil fertilization (at rates of 0.16 and $0.32 \mathrm{~g} \mathrm{Si} / \mathrm{kg}$ ) also conferred protection to poorly resistant cultivars (Han et al., 2015). The authors of this study concluded that it was due to the reduced quality/digestibility of the leaf, due to higher silicon content of the leaf, rather than the silicon acting as an active deterrent to leaf consumption. This contrasts with a plant physiological investigation into the effects of rice leaf folder. Rice silicon concentrations and transcript levels, including lsi1 and lsi2 were measured to study the impacts of silicon on a wild-type rice and it's jasmonate synthesis pathways RNAi knockdown (Ye et al., 2013). The authors concluded that there was a strong interaction of silicon and the jasmonate signaling pathway. Silicon pre-treatment led to higher levels of jasmonate production and increased expression of a range of defense related genes in the wild-type. Reduced levels of silicon were observed in knockdown mutant leaves. Furthermore, reduced levels of lsi1, lsi2 and lsi6 transcripts were observed in this study in knockdowns after insect attack.

Stem borer resistance (Chilo suppressalis) was also enhanced by silicon addition to soil, with maximal effect seen at $20 \mathrm{~g}$ silicon $/ \mathrm{kg}$ (Kanew et al. 2012). This silicon induced resistance to the stem borer appears to be physical with enhanced silicon content causing decreased borer penetration, resulting in lower weight gain and stem damage (Hou and Han, 2010). This weight gain reduction 
increased the length of the larval stage, making the borer more prone to predation.

Enhanced leaf silicon also provides resistance to planthoppers (Ma and Takahashi, 2002). Yoshihara et al. (1979) found that elevated silicic acid in the phloem inhibited brown planthopper (Nilaparvata lugens) feeding. Another study, that of He et al. (2015b), found that increased plant silicic acid content caused a decrease in planthopper residence time on the plant, a decrease in fertility and a decrease in honeydew production.

It appears that silicon defense against insects is threefold: a. enhanced physical protection of the leaf for attack/colonization, b. the leaf being a poorer quality substrate as silicon makes it less digestible and results in lower macro-nutrient content and c. the phenology of the insects' life-cycle is slowed down, also making it more prone to predation. Silicon content regulation of biochemical pathways may also play a role (Van Bockhaven et al., 2013).

\subsection{Abiotic stress mitigation}

Silicon in outer walls of the stems and the silicon content correlates with bending strength and, thus, lodging resistance (Liang et al., 2013). A study by Goto et al. (2003) showed that silicon fertilization leads to enhanced UV tolerance due the protective effect of deposition of silicon bodies in the leaf epidermis. Increased silicon nutrition enhanced photosynthesis, probably through enhanced mesophyll conductance (Detmann et al., 2012). 
Drought stress is mitigated by silicon (Khattab et al., 2014; Nolla et al., 2012). In an elegant soil based experiment conducted by Nolla et al. (2012), where upland rice was grown in two different savanna soils held at 60,70 and $80 \%$ of water holding capacity and calcium silicate fertilized at 0, 200, 400 and 600 $\mathrm{kg} / \mathrm{ha} /$ year, silicon fertilization enhanced yields under water stress. There is evidence that abscisic acid, known to mediate drought-induced growth arrest, targets support cells in mature tissue (Shobbar et al., 2008). In this study it was shown that abscisic acid induced accumulation of transcripts in the cytosol of major support cells, including epidermal silicon cells, thereby linking abscisic acid signaling to silicon deposition. Furthermore, expression of lsi1 was shown to be regulated by abscisic acid and by dehydration stress, suggesting a role in drought in regulating this proteins' expression (Yamaji and Ma, 2007).

Silicon fertilization enhances sodium tolerance in rice (Kim et al., 2014). Silicon fertilization reduced transport of chloride to shoots in 3 rice cultivars (Shi et al., 2013). Decreased chloride transport was correlated with a decrease in transpirational bypass flow (Shi et al., 2013; Yeo et al., 1999). Silicon fertilization increased stomatal conductance and net photosynthetic rate. The fact that silicon fertilization increased the net photosynthetic rate, stomata conductance, and transpiration of salt-stressed plants, showed that decrease in sodium and chloride transport to shoots in salt sensitive cultivars was not due to a decrease in the transpiration rate, and that the transpirational bypass flow change was the major factor in silicon decreasing chloride transport to shoots (Shi et al., 2013). A mechanistic study of how silicon ameliorates sodium stress in rice provided evidence that enhanced silicon content in both root and shoot endodermis 
reduced silicon uptake by the root. This was achieved by reducing apoplastic transport and, again, was not due to alteration of transpiration. (Gong et al., 2006). It was specifically sodium uptake that was altered by silicon with no effects on potassium uptake and transport.

There is some evidence that silicon fertilization, at least in hydroponic solution, ameliorates iron(II) toxicity. Enhanced silicon in the growth solution decreased iron plaque formation on the rhizoplane and increased iron transport to shoot, though the mechanistic basis of these observations was not investigated (Fu et al., 2012). Manganese toxicity is also ameliorated by silicon in hydroponics with enhanced plant silicon content restricting manganese transport to the shoot in one cultivar and decreasing root assimilation in another (Li et al. 2012). This decreased manganese uptake and transport led to decreased redox stress in the plant tissues. Similar findings have also been reported for zinc where the enhanced cell wall binding of zinc in silicon replete plants has been implicated in restricting zinc uptake into roots and transport to shoots (Gu et al., 2012; Song et al., 2011). Silicon fertilization in hydroponic studies was furthermore found to decrease aluminum (Hara et al., 1999; Singh et al. 2011), and chromium (Zeng et al., 2011) uptake by plants. Fertilizer, silicon applied as fly-ash or steel slag to multi-metal contaminated soil affected both root uptake and shoot translocation of cadmium, copper, lead and zinc (Gu et al., 2011). The action of silicon appeared 2-fold. Toxic metals were precipitated in soil in the presences of silicon fertilizer to corresponding silicates, phosphates and hydroxides, while enhanced shoot silicon restricted transport of these metals into leaves from stems. 
It has to be noted that the effect of silicon on abiotic resistance is not always positive. When soils fertilized with $600 \mathrm{~kg} / \mathrm{ha} /$ year $\mathrm{SiO}_{2}$, were subsequently subjected to $12 \mathrm{~d}$ submergence, silicon fertilization decreased rice survival (Ella et al., 2011). Four genotypes were studied, including flooding sensitive and insensitive, but there was no silicon times genotype interaction. The mechanistic basis of this is unclear though survival was correlated negatively with chlorophyll degradation, carbohydrate depletion and shoot elongation during submergence.

\section{Grain quality and silicon}

Silicon fertilization appears to mitigate against accumulation of inorganic arsenic, antimonite and cadmium in rice grain. Arsenic, antimonite and cadmium are toxic at elevated concentrations and if accumulated in rice grain, present potential threat to human health. The interconnected pathways of silicon with arsenic and cadmium (and iron), from soil particles to shoot epidermal cells, are illustrated in Figure 2.

\subsection{Silicon on inorganic arsenic, antimony and selenite uptake}

Arsenite, antimonite and selenite are all silicic acid analogues with respect to their assimilation by rice roots. Antimonite and arsenite are potent carcinogens while selenium (as a range of species) is an essential element.

Inorganic arsenic in rice grain is a global problem as rice is the dominant source of this carcinogen to the human diet (Meharg et al., 2009). Arsenite, the prevalent form of arsenic under anaerobic conditions in paddy soils, is a silicic 
acid analogue and rice is efficient at assimilating arsenite. A range of studies has found that excess silicon, either in soil or hydroponic culture, reduces inorganic arsenic uptake and translocation to plant shoots and grain (i.e. Fleck et al., 2013; Liu et al., 2014b; Li et al., 2009; Seyfferth et al., 2012). When the availability of arsenic in soil solution was correlated to natural soils solution silicic acid across 6 soil types, it was observed that higher silicic acid in soil solution inhibited arsenic assimilation by rice (Bogdan and Schenk, 2008). Addition of sparingly soluble silicate gel to paddy soils decreased the accumulation of inorganic arsenic, but enhanced the uptake of dimethylarsinic acid (DMA) (Liu et al., 2014b; Li et al., 2009). It was postulated that this enhanced DMA assimilation was due to dissolved silicic acid derived from the silicate gel outcompeting DMA for soil exchange sites, enhancing it's concentration in soil solution (Liu et al., 2014b). Similar to Liu et al. (2014b), Fleck et al. (2013) found that wholegrain DMA was decreased by silicon addition, but that polished rice concentrations were identical in plants that had or had not received silicon supplementation to their soils. This silicon fertilization of paddy soils reduced arsenic concentrations in wholegrain rice by $22 \%$. They found that silicon fertilization enhanced silicon, iron, phosphorus and arsenic in soil solutions, but postulate that the enhanced silicon in the soil solution, or in plant tissue out-competes arsenite transport, ultimately leading to lower grain concentrations. In a study comparing diatomaceous earth with silica-gel fertilized paddy soils, with respect to these amendments impact on silicon and arsenic uptake into the plant, it was found that diatomaceous earth was not efficacious at either releasing silicon into soil solution or in affecting plant arsenic levels, where silica-gel did both (Seyfferth et 
al., 2012). It was postulated that silicon, as silicic acid, released from the gel outcompeted arsenite for uptake.

There is strong evidence that inorganic arsenic is remobilized from leaves during grain fill through phloem transport (Carey et al., 2011). When the silicon content of rice leaves was correlated with grain arsenic in the field, a strong positive relationship was found, with the arsenic present predominantly in its inorganic form (Norton et al., 2010). So while silicic acid may compete with arsenite for root uptake, plants that are genetically more efficient at assimilating silicon will have higher loadings of inorganic arsenic.

Rice is also a source of the environmental pollutant antimonite, a carcinogen, and toxicant causing diseases of the liver, skin, respiratory, cardiovascular systems (Wu et al., 2011, Ren et al., 2014). Antimonite is, like arsenite, also a silicic acid analogue and presence of silicic acid in solution culture was also shown to reduce uptake of antimonite in rice (Huang et al., 2012, Tripathi et al. 2013).

There is also physiological evidence for a role in silicic acid transporters in selenite uptake, again with selenite acting as a silicic acid analogue (Zhao et al., 2010), though the impact of this pathway on grain nutrition is not known. Given that selenium is an essential nutrient, often deficient in rice, and in humans, this elucidates that selenium species uptake pathways in rice are important.

\subsection{Effect of silicon on cadmium uptake}


Rice is also the dominant source of the carcinogen and renal toxicant cadmium into the human diet (Meharg et al., 2013). Silicon fertilization is known to reduce cadmium uptake and transport by rice (Triaparthi et al., 2012; Wang et al., 2000), and to enhance cadmium tolerance (Nwugo and Huerta, 2008; Wang et al., 2000), though the mechanisms is not well understood. Silicon was found to cross-link with cell wall hemi-celluloses (Ma et al., 2015). It was postulated that the negative charge of these silicon complexes in the cell wall may lead to enhanced cadmium binding and, thereby, inhibit cadmium transport within the rice plant (Liu et al., 2013; Ma et al., 2015). In a time-course study by Zhang et al. (2008) silicon fertilization decreased cadmium assimilation by the plant and decreased cadmium toxicity in solution culture. Stimulation of plant biomass by silicon was a potential route of mitigation of cadmium, as was the deposition of cadmium in phytoliths, as observed by energy-dispersive X-ray micro-analysis. The experiments of Wang et al. (2000) also suggested that cadmium was precipitated by colloidal silicon in cells.

\section{Future directions}

Silicon appears to be a silver bullet for rice in counteracting both biotic and abiotic stress, leading to higher yields, as well as improving the quality of grain through decreasing cadmium, antimony and arsenic contents. Silicon may, furthermore, enhance grain selenium concentrations. The benefits of silicon nutrition to rice are outlined in Figure 3. However, as rice is efficient at stripping plant available silicon from soils the challenge is how to effectively cycle and sustain silicon levels in soil. The answer is two-fold: rice genetics and silicon fertilization. 
While the specific mechanisms of silicon accumulation by rice roots are now well understood, i.e. lsi1 and lsi2, the basis of genetic variance in shoot silicon content between cultivars is not. Quantitative trait loci (QTL) studies have identified variance in shoot and hull silicon content (Bryant et al. 2011, Dai et al., 2005, 2008; Gong et al., 2010). Twelve QTL markers were found for hull silica content with 6 of these also coinciding with markers for silicon content found in other studies (Bryant et al., 2011). If the genes responsible for these QTLs can be identified, this will be the start of a mechanistic understanding of the regulation of the plants silicon status, plus aid in the accelerated breeding for desirable traits. Wider screening, and subsequent genetic analysis, of rice germplasm for high shoot silicon and enhanced efficiency of root assimilation from recalcitrant soil pools is another key strategy for breeding rice that is higher in silicon status.

Inorganic silicon fertilizers are finite and are related to industrial processing of iron and steel and, thus, availability of inorganic silicon fertilizers are related to local economy and, therefore, patchily distributed. Also, as issues regarding toxic elements in rice grain come to the fore, particularly cadmium (Meharg et al., 2013) and arsenic (Meharg et al., 2009), the trace metal contamination of slag, which has always been an issue regarding nickel and chromium (Ma and Takahashi 2002), needs further examination (Ganne et al. 2006; Houben et al., 2013). However, slag has been suggested as remediation agent for both arsenic (Li et al., 2006) and cadmium (Zhou et al., 2012), so the balance of the risks and benefits of slag with respect to arsenic and cadmium rice grain concentrations needs exploring. 
Perhaps a more sustainable strategy with respect to silicon fertilization is to increase the once common practice (Ma and Takahashi, 2002) of reincorporating composted rice straw back into paddy fields. This results in returning the vast bulk of silicon removed by the crop in a highly bioavailable form, by ensuring continuous cycling of phytoliths. Composting of rice straw, due to its high silicon content, is slow, needs valuable space in which to perform the compositing, and is time consuming, which explains the sharp decline in rice composting observed in countries such as Japan (Ma and Takahashi, 2002). The accelerated composting of rice straw needs some attention, such as via the use of fungal inoculants (Viji and Neelenarayanan, 2015), as well as the co-composting of straw alongside animal manures (Zhu, 2007). In particular use of manures produced from animals that consume rice straw (Song et al. 2014) as well as use of biochars derived from rice straw (Xiao et al. 2014) or husks (Ma and Takahashi, 2002) in composting or as soil amendment may provide a way forward.

Ultimately, if silicon can be more efficiently recycled, and plants bred for high silicon content, considerably improved yields of high quality grain will be achieved, along with decreased requirements for pesticide usage. High silicon rice is better adapted to the biotic and abiotic stresses that climate change will bring. Silicon can indeed be seen as the silver bullet for mitigating biotic and abiotic stress, and improving grain quality, in rice. Optimization of silicon's biogeochemical cycling in paddy environments is, therefore, on all accounts, a good long-term agricultural policy with great potential benefit to the global economy: It will help feed an expanding population, as will deliver increased 
yield and higher quality rice crops (increase in essential nutrients i.e. selenium, decrease the carcinogens arsenic and cadmium), while at the same time leading to increased sustainability of the paddy soil system and decrease in agriculturally mediated pollution, i.e. tighter nutrient cycling, reduced requirements for pesticides.

\section{References}

Abed-Ashtiani, F., Kadir, J-B., Selamat, A-B., Hanif, A.H.B-M., Nasehi, A. 2012.

Effect of Foliar and Root Application of silicon against rice blast fungus in MR219 vice variety. Plant Pathol. J. 28, 164-171.

Bogdan, K., Schenk, M.K. 2008. Arsenic in rice (Oryza sativa L.) related to dynamics of arsenic and silicic acid in paddy soils. Environ. Sci. Technol. 42, 7885-780.

Brunings, A.M., Datnoff, L.E., Ma, J.F., Mitani, N., Nagamura, Y., Rathinasabapathi, B., Kirst, M. 2009. Differential gene expression of rice in response to silicon and rice blast fungus Magnaporthe oryzae. An. Appl. Biol. 155, 161-170.

Bryant, R., Proctor, A., Hawkridge, M., Jackson, A., Yeater, K., Counce, P., Yan, W., McClung, A., Fjellstrom, R. 2011. Genetic variation and association mapping of silica concentration in rice hulls using a germplasm collection. Genetica 139, 1112.

Cai, K., Gao, D., Luo, S. Zeng, R., Yang, J. Zhu, X. 2008. Physiological and cytological mechanisms of silicon-induced resistance in rice against blast disease. Physiol. 
Plant. 2008, 324-333.

Carey, A.M., Lombi, E., Donner, E., de Jonge, M.D., Punshon, T., Jackson, B.P., Guerinot, M.L., Price, A.H., Meharg, A.A. 2012. A review of recent developments in the speciation and localization of arsenic and selenium un rice grain. Anal. Bioanal. Chem. 402, 3275-3286.

Carey, A.M., Norton, G.J., Deacon, C., Scheckel, K.G., Lombi, E., Punshon, T., Guerinot, M.L., Lanzirotti, A., Newville, M., Choi, Y., Price, A.H., Meharg, A.A. 2011. Phloem transport of arsenic species from flag leaf to grain during grain filling. New Phytol. 192, 87-98.

Dai, W.M., Zhang, K.Q., Duan, B.W., Zheng, K.L., Zhuang, J.Y., Cai, R. 2005. Genetic dissection of silicon content in different organs of rice. Crop Sci. 45, 1345-1352.

Dai, W.M., Zhang, K.Q., Wu, J.R., Wang, L., Duan, B.W., Zheng, K.L., Cai, R., Zhuang, J.Y. 2008. Validating a segment on the short arm of chromosome 6 responsible for genetic variation in the hull silicon content and yield traits of rice. Euphytica $160,317-324$.

Dallagnol, L.J., Rodrigues, F.A., DaMatta, F.M., Mielli, M.V., Pereira, S.C. 2011. Deficiency in silicon uptake affects cytological, physiological, and biochemical events in the rice-Bipolaris oryzae interaction. Phytopathology 101(1):92-104.

Dallagnol, L.J., Rodrigues, F.A., Chaves, A.R.M., Vale, F.X.R., DaMatta, F.M. 2013. 
Photosynthesis and sugar concentration are impaired by the defective active silicon uptake in rice plants infected with Bipolaris oryzae. Plant Pathol. 62, 120129.

Dallagnol, L.J., Rodrigues, F.A., Mielli, M.V.B., Ma, J.F. 2014. Rice grain resistance to brown spot and yield are increased by silicon. Trop. Plant Pathol. 39, 56-63.

Datnoff, L.E., Snyder, G.H., Deren, C.W. 1992. Influence of silicon fertilizer grads on blast and brown spot development and rice yields. Plant Dis. 76, 1011-1-13.

Deren, C.W., Datnoff, L.E., Snyder, G.H., Martin, F.G. 1994. Silicon concentration, disease response, and yield components of rice genotypes grown on flooded organic histosols. Crop Sci. 23, 733-737.

Desplanques, V., Cary, L., Mouret, J.C., Trolard, F., Bourrie, G., Grauby, O., Meunier, J.D. 2006. Silicon transfers in a rice field in Camargue (France). J Geochem. Explor. 88, 190- 193.

Detmann, K.C., Araujo, W.L., Martins, S.C.V., Sanglard, L.M.V.P., Reis, Josimar V., Detmann, E., Rodrigues, F.A., Nunes-Nesi, A., Fernie, A.R., DaMatta, F.M. 2012. Silicon nutrition increases grain yield, which, in turn, exerts a feed-forward stimulation of photosynthetic rates via enhanced mesophyll conductance and alters primary metabolism in rice. New Phytol. 196, 752-762.

Ella, E.S., Dionisio-Sese, M.L., Ismail, A.M. 2011. Application of silica before 
sowing negatively affects Growth and survival of rice following submergence. Philip. J. Crop Sci. 36, 1-11.

Epstein, E. Silicon. Ann. Rev. Plant Physiol. Plant Mol. Biol. 1999, 50, 641-664.

Fleck, A.T., Mattusch, J., Schenk, M.K. 2013. Silicon decreases the arsenic level in rice grain by limiting arsenite transport. J. Plant Nutr. Soil Sci. 176, 785-794.

Fleck, A.T., Nye, T., Repenning, C., Stahl, F., Zahn, M., Schenk, M.K. 2011. Silicon enhances suberization and lignification in roots of rice (Oryza sativa). J. Exp. Bot. 62, 2001-2011.

Fu, Y.Q., Shen, H., Wu, D.M., Cai, K.Z. 2012. Silicon-mediated amelioration of Fe2+ toxicity in rice (Oryza sativa L.) roots. Pedosphere 22, 795-802.

Ganne, P., Cappuyns, V., Vervoot, A.; Buve, L., Swennen, R. 2006. Leachability of heavy metals and arsenic from slags of metal extraction industry at Angleur (eastern Belgium). Sci. Total Environ. 356, 69-85.

Gong, H.J., Randall, D.P., Flowers, T.J. 2006. Silicon deposition in the root reduces sodium uptake in rice (Oryza sativa L.) seedlings by reducing bypass flow. Plant Cell Environ. 29, 1970-1979.

Gong, J.Y., Wu, J.R., Wang, K., Fan, Y.Y., Zhuang, J.Y. 2010. Fine mapping of qHUS6.1, a quantitative trait locus for silicon content in rice (Oryza sativa L.). 
Chinese Sci. Bull. 55, 3283-3287.

Goto, M., Ehara, H., Karita, S., Takabe, K., Ogawa, N., Yamada, Y., Ogawa, S., Yahaya, M.S., Morita, 0. 2003. Protective effect of silicon on phenolic biosynthesis and ultraviolet spectral stress in rice crop. Plant Sci, 164, 349-356.

Gu, H.H., Qiu, H., Tian, T., Zhan, S.S., Deng, T.H.B., Chaney, R.L., Wang, S.Z., Tang, Y.T., Morel, J.L., Qiu, R.L. 2011. Mitigation effects of silicon rich amendments on heavy metal accumulation in rice (Oryza sativa L.) planted on multi-metal contaminated acidic soil. Chemosphere 83, 1234-1240.

Gu, H.H., Zhan, S.S., Wang, S.Z., Tang, Y.T., Chaney, R.L., Fang, X.H., Cai, X.D., Qiu, R.L. 2012. Silicon-mediated amelioration of zinc toxicity in rice (Oryza sativa L.) seedlings. Plant Soil 350, 193-204.

Han, Y., Lei, W., Wen, L., Hou, M. 2015. Silicon-mediated resistance in a susceptible rice variety to the rice leaf folder, Cnaphalocrocis medinalis Guenee (Lepidoptera: Pyralidae). PloSone 10, e0120557.

Hara, T., Gu, M.H., Koyama, H. 1999. Ameliorative effect of silicon an aluminum injury in the rice plant. Soil Sci, Plant Nutr. 45, 929-936.

Hayasaka, T., Fujii, H., Ishiguro, K. 2008. The role of silicon in preventing appressorial penetration by the rice. Phytopath. 
$98,1038-1044$.

Haynes, R.J. 2014. A contemporary overview of silicon availability in agricultural soils. J. Plant Nutr. Soil Sci. 177, 831-844.

He, C. Ma, J., Wang, L. 2015a. A hemicellulose-bound form of silicon with potential to improve the mechanical properties and regeneration of the cell wall of rice. New Phytol. 206, 1061-1062.

He, W., Yang, M., Li, Z., Qiu, J., Liu, F., Qu, X., Qiu, Y., Li, R.2051b. High levels of silicon provided as a nutrient in hydroponic culture enhances rice plant resistance to brown planthopper. Crop Protect. 67, 20-25.

Hosseini, S.Z., Jelodar, N.B., Bagheri, N. 2012. Study of silicon effects on plant growth and resistance to stem borer in rice. Comm. Soil Sci. Plant Anal. 43, 27442751.

Hou, M., Han, Y. 2010. Silicon-mediated rice plant resistance to the Asiatic rice borer (Lepidoptera: Crambidae): Effects of silicon amendment and rice varietal resistance. J. Econ. Entomol. 103, 1412-1419.

Houben, N., Couder, E., Sonnet, P. 2013. Leachability of cadmium, lead, and zinc in a long-term spontaneously revegetated slag heap: implications for phytostabilization. J. Soil Sed. 13, 543-554. 
Huang, Y.Z., Zhang, W.Q., Zhao, L.J. 2012. Silicon enhances resistance to antimony toxicity in the low-silica rice mutant, lsi1. Chem. Ecol. 28, 341-354.

Kanew, S.R., Choi, H., Kim, J.Y., Vigneswaren, S., Shim, W.G. 2006. Removal of arsenic (III) from groundwater using low-cost industrial by-products - blast furnace slag. Water Qual. Res. J. Canada 41, 130-139.

Khattab, H.I., Emam, M.A., Emam, M.M., Helal, N.M., Mohamed, M.R. 2014. Effect of selenium and silicon on transcription factors NAC5 and DREB2A involved in drought-responsive gene expression in rice. Biol. Plant. 58, 265- 273.

Kido, N., Yokoyama, R., Yamamoto, T. Furukawa, J., Iwai, H., Satoh, S., Nishitani, K. 2015. The matrix polysaccharide $(1 ; 3,1 ; 4)$-beta-d-glucan is involved in silicondependent strengthening of rice cell wall. Plant Cell Physiol. 56, 268-276.

Kim, Y.H., Khan, A.L., Waqas, M., Shim, J.K., Kim, D.H., Lee, K.Y., Lee, I.J. 2014. Silicon application to rice root zone influenced the phytohormonal and antioxidant responses under salinity stress. J. Plant Growth Regul. 33, 137-149.

Korndorfer, G.H., Snyder, G.H., Ulloa, M., Powell, G., Datnoff, L.E. 2001. Calibration of soil and plant silicon analysis for rice production. J. Plant Protect. 24, 10711084.

Li, R.Y., Stroud, J.L., Ma, J.F., McGrath, S.P., Zhao, F.J. 2009. Mitigation of arsenic accumulation in rice with water management and silicon fertilization. Environ. 
Sci. Technol. 43, 3778-3783.

Li, P., Song, A., Li, Z., Fan, F., Liang, Y. 2012. Silicon ameliorates manganese toxicity by regulating manganese transport and antioxidant reactions in rice (Oryza sativa L.). Plant Soil 354, 407-419.

Li, Z., Song, Z., Cornelis, J.T. 2014. Impact of rice cultivar and organ on elemental composition of phytoliths and the release of bio-available silicon. Front. Plant Sci. 5, 529, DI 10.3389/fpls.2014.00529.

Liang, S.J., Li, Z.Q., Li, X.J., Xie, H.G., Zhu, R.S., Lin, J.X., Xie, H.A., Wu, H. 2013. Effects of stem structural characters and silicon content on lodging resistance in rice (Oryza sativa L.). Res. Crops 14, 621-636.

Liang, Y.C., Ma, T.S., Li, F.J., Feng, Y.J. 1994. Silicon availability and response of rice and wheat to silicon in calcareous soils. Comm. Soil Sci. Plant Anal. 25. 2285-2297.

Liu, J., Ma, J., He, C., Li, X., Zhang, W., Xu, F., Lin, Y., Wang, L. 2013. Inhibition of cadmium ion uptake in rice (Oryza sativa) cells by a wall-bound form of silicon. New Phytol. 200, 691-699.

Liu, M., Cai, K., Chen, Y., Luo, S., Zhang, Z., Lin, W. 2014a. Proteomic analysis of silicon-mediated resistance to Magnaporthe oryzae in rice (Oryza sativa L.). Eur. J. Plant Pathol. 139, 579-592. 
Liu, W.J., McGrath, S.P., Zhao, F.J. 2014b. Silicon has opposite effects on the accumulation of inorganic and methylated arsenic species in rice. Plant Soil 376, 423-431.

Ma, J., Cai, H., He, C., Zhang, W., Wang, L. 2015. A hemicellulose-bound form of silicon inhibits cadmium ion uptake in rice (Oryza sativa) cells. New Phytol. 206, 1063-1074.

Ma, J.F., Takahashi, E., 2002. Soil, Fertilizer and Plant Silicon Research in Japan. Elsevier, Amsterdam.

Ma, J.F., Tamai, K., Yamaji, N., Mitani, N., Konishi, S., Katsuhara, M., Ishiguro, M., Murata, Y., Yano, M., 2006. A silicon transporter in rice. Nature. 440. 688-691.

Ma, J.F., Yamaji, N., Mitani, N., Tamai, K., Konishi, S., Fujiwara, T., Katsuhara, M. Yano, M. 2007a. An efflux transporter of silicon in rice. Nature. 448, 209. DI 10.1038/nature05964.

Ma, J.F., Yamaji, N., Tamai, K., Mitani, M. 2007b. Genotypic differences in silicon uptake and expression of silicon transporter genes in rice. Plant Physiol. 145, 915-924.

Marschner, P. 2012. Mineral Nutrition of Higher Plants. Elsevier, Amsterdam. 
Meharg, A.A., Jardine, L. 2003. Arsenite transport into paddy rice (Oryza sativa) roots. New Phytol. 157, 39-44.

Meharg, A.A., Norton, G., Deacon, C., Williams, P.N., Adamako, E., Price, A., Zhu, Y.G., Zhao, F.J., Villada, A., Sommella, A., De Silva, M.S.S., Bremmer, H., Dasgupta, T., Islam, R. 2013. Variation in cadmium in rice related to human exposure. Environ. Sci. Technol. 47, 5613-5618.

Meharg, A.A., Williams, P.N., Adamako, E., Lawgali, Y.Y., Deacon, C., Villada, A., Cambell, R.C.J., Sun, G.X., Zhu, Y.G., Feldmann, J., Raab, A., Zhao, F.J., Islam, R., Hossain, S., Yanai, J. 2009 Geographical variation in total and inorganic arsenic content of polished (white) rice. Environ. Sci. Technol. 43, 1612-1617.

Nakata, Y., Uena, M., Kihara, J., Ichii, M., Taketa, S., Arase, S., 2008. Rice blast disease and susceptibility to pests in a silicon uptake-deficient mutant lsil of rice. Crop Protect. 27, 865-868.

Ning, D., Song, A., Fan, F., Li, Z., Liang, Y. 2014. Effects of slag-based silicon fertilizer on rice growth and brown-spot resistance. PLOSone 9, e102681. Nolla, A., de Faria, R.J., Korndoerfer, G.H., Benetoli da Silva, T.R. 2012. Effect of silicon on drought tolerance of upland rice. J. Food Agric. Environ. 10, 269-272.

Norton, G.J., Islam M.R., Duan, G., Lei, M., Zhu, Y.G., Deacon, C.M., Moran, A.C.,, Islam, S., Zhao, F.J., Stroud, J.L., McGrath, S.P., Feldmann, J., Price, A.H., Meharg, 
A.A. 2010 Arsenic Shoot - Grain Relationships in Field Grown Rice Cultivars. Environ.l Sci. Technol. 44, 1471-1477.

Nwugo, C.C., Huerta, A.J. 2008. Silicon-induced cadmium resistance in rice (Oryza sativa). J. Plant Nutr. Soil Sci. Zeit. Pflanz. Bodn. 171, 841-848.

Pereira, H.S., Korndorfer, G.H., Vidal, A.D., de Camargo, M.S. 2004. Silicon sources for rice crop. Sci. Agric. 61, 522-528.

Prabhu, A.S., Barbosa. F., Morel, P., Datnoff, L.E., Snyder, G.H., Berni, R.F., Rodrigues, F.A., Dallagnol, L.J. 2012. Silicon reduces brown spot severity and grain discoloration on several rice genotypes. Trop. Plant Pathotl. 37, 409-414.

Ren, J.H., Ma, LQ., Sun, H.J., Cai, F., Luo, J. 2014. Antimony uptake, translocation and speciation in rice plants exposed to antimonite and antimonate. Sci Total Environ. 475:83-89.

Rezende, D.C., Rodrigues, F.A., Carre-Missio, V., Schurt, D.A., Kawamura, I.K., Korndorfer, G.H. 2009. Effect of root and foliar applications of silicon on brown spot development in rice. Aust. J. Plant Physiol. 38, 67- 73.

Schurt, D.A., Cruz, M.F.A., Nascimento, K.J.T., Filippi, M.C.C., Rodrigues, F.A. 2014. Silicon potentiates the activities of defense enzymes in the leaf sheaths of rice plants infected by Rhizoctonia solani. Trop. Plant Pathol. 39, 457-463. 
Schurt, D.A., Rodrigues, F.A., Reis, R.D., Moreira, W.R., Abreu, S., Naiara F., Silva, W.A. 2012. Physical resistance of leaf sheaths of rice plants supplied with silicon and infected by Rhizoctonia solani. Trop. Plant Pathol. 37, 281-285.

Schurt, D.A., Rodrigues, F.A., Colodette, J.L., Carre-Missio, V. 2013. Effect of silicon on lignin and sugar concentrations of leaf sheaths in rice plants infected by Rhizoctonia solani. Bragantia 72, 360-366.

Seyfferth, A.L., Fendorf, S. 2012. Silicate mineral impacts on the uptake and storage of arsenic and plant nutrients in rice (Oryza sativa L.). Environ. Sci. Technol. 46, 13176-13183.

Seyfferth, A.L., Kocar, B.D., Lee, J.A., Fendorf, S. 2013. Seasonal dynamics of dissolved silicon in a rice cropping system after straw incorporation. Geochem. Cosmochim. Acta 123, 120-133.

Shi, Y., Wang, Y., Flowers, T.J., Gong, H. 2013. Silicon decreases chloride transport in rice (Oryza sativa L.) in saline conditions. J. Plant Physiol. 170, 847-853.

Shobbar, Z.S., Oane, R., Gamuyao, R., De Palma, J. Malboobi, M.A., Karimzadeh, G., Javaran, M.J., Bennett, J. 2008. Abscisic acid regulates gene expression in cortical fiber cells and silica cells of rice shoots. New Phytol. 178, 68-79.

Singh, V.P., Tripathi, D.K., Kumar, D., Chauhan, D.K., 2011. Influence of exogenous silicon addition on aluminium tolerance in rice seedlings. Biol. Trace Elemen. 
Res. 144, 1260-1274.

Sommer, M., Kaczoek, D., Kuzyakov, Y., Breuer, J. 2006. Silicon pools and fluxes in soils and landscapes - a review. J. Plant Nutr. Soil Sci. 169, 310-329.

Song, A., Li, P., Li, Z., Fan, F., Nikolic, M., Liang, Y. 2011. The alleviation of zinc toxicity by silicon is related to zinc transport and antioxidative reactions in rice. Plant Soil 344, 319-333.

Song, Z., Wang, H., Strong, P.J., Shan, S., 2014. Increase of available soil silicon by Si-rich manure for sustainable rice production. Agron. Sustain. Devel. 34, 813819.

Sun, W., Zhang, J., Fan, Q., Xue, G., Li, Z., Liang, Y. 2010. Silicon-enhanced resistance to rice blast is attributed to silicon-mediated defense resistance and its role as physical barrier. Eur. J. Plant Pathol. 128, 39- 49.

Suzuki, S., Ma, J.F., Yamamoto, N., Hattori, T., Sakamoto, M., Umezawa, T. 2012. Silicon deficiency promotes lignin accumulation in rice. Plant Biotech. 29, 391394.

Tavakkoli, E., Lyons, G., English, P., Guppy, C.N. 2011. Silicon nutrition of rice is affected by soil pH, weathering and silicon fertilization. J. Plant Nutr. Soil Sci. 174, 437-446. 
Tripathi, D.K., Singh, V.P., Kumar, D., Chauhan, D.K., 2012. Rice seedlings under cadmium stress: effect of silicon on growth, cadmium uptake, oxidative stress, antioxidant capacity and root and leaf structures. Chem. Ecol. 28, 281-291.

Tripathi, P., Tripathi, R.D., Singh, R.P., Dwivedi, S., Goutam, D., Shri, M., Trivedi, P.K., Chakrabarty, D. 2013. Silicon mediates arsenic tolerance in rice (Oryza sativa L.) through lowering of arsenic uptake and improved antioxidant defense system. Ecol. Engin. 52, 96-103.

Van Bockhaven, J., De Vleesschauwer, D., Hofte, M. 2013. Towards establishing broad-spectrum disease resistance in plants: silicon leads the way. J. Exp. Bot. 64, 1281-1293.

Van Bockhaven, J., Spichal, L., Novak, O., Strnad, M., Asano, T., Kikuchi, S., Hofte, M., De Vleesschauwer, D., 2015. Silicon induces resistance to the brown spot fungus Cochliobolus miyabeanus by preventing the pathogen from hijacking the rice ethylene pathway. New Phytol. 206, 761-773.

Viji, J., Neelenarayanan, P. 2015. Efficacy of lignocellulolytic fungi on the biodegradation of paddy straw. Int. J. Environ. Res. 9, 252-232.

Wang, L.J., Wang, Y.H., Chen, Q., Cao, W.D., Li, M., Zhang, F.S. 2000 Silicon induced cadmium tolerance of rice seedlings. J. Plant Nutr. 23, 1397-1406.

Wu F., Fu Z., Liu B., Mo C., Chen B., Corns W., Liao H. 2011. Health risk associated 
with dietary co-exposure to high levels of antimony and arsenic in the world's largest antimony mine area. Sci Total Environ. 409(18):3344-3351.

Wu, Q.S., Wan, X.Y., Su, N., Cheng, Z.J., Wang, J.K., Lei, C.L., Zhang, X., Jiang, L., Ma, J.F., Wan, J.M. 2006. Genetic dissection of silicon uptake ability in rice (Oryza sativa L.). Plant Sci. 171, 441-448.

Xiao, X., Chen, B., Zhu, L. 2014. Transformation, Morphology, and dissolution of silicon and carbon in rice straw-derived biochars under different pyrolytic temperatures. Environ. Sci, Technol. 48, 3411-3419.

Yamaji, N., Ma, J.F. 2007. Spatial distribution and temporal variation of the rice silicon transporter Lsi1. Plant Physiol. 143, 1306-1313.

Yamaji, N., Ma, J.F. 2009. A transporter at the node responsible for intervascular transfer of silicon in rice. Plant Cell 21, 2878-2883.

Yamaji, N., Mitatni, N., Ma, J.F. 2008. A transporter regulating silicon distribution in rice shoots. Plant Cell 20, 1381-1389.

Yamamoto, T., Nakamura, A., Iwai, H., Ishii, T., Ma, J.F. 2012. Effect of silicon deficiency on secondary cell wall synthesis in rice leaf. J. Plant Res. 125, 771-779.

Ye, M., Song, Y., Long, J., Wang, R., Baerson, S.R., Pan, Z., Zhu-Salzman, K., Xie, J., Cai, K., Luo, S., Zeng, R. 2013. Priming of jasmonate-mediated antiherbivore 
defense responses in rice by silicon. Proc. Nat. Acc. Am. 110, 3631-3639.

Yeo, A.R., Flowers, S.A., Rao, G., Welfare, K., Senanayake, N., Flowers, T.J. 1999.

Silicon reduces sodium uptake in rice (Oryza sativa L.) in saline conditions and this is accounted for by a reduction in the transpirational bypass flow. Plant Cell Environ. 22, 559-565.

Yoshihara, T., Sogawa, H., Pathak, M.D., Juliano, B.O., Sakamura, S. (1979) Soluble silicic acid as sucking inhibitory substance in rice against the brow plant hopper (Delphacidae, Homoptera). Entomol. Exp. Applica. 26, 314-322.

Zeng F., Zhao, F., Qiu, B., Ouyang Y., Wu F., Zhang G. 2011. Alleviation of chromium toxicity by silicon addition in rice plants. Agric. Sci. China 10, 11881196.

Zhang, G., Cui, Y., Ding, X., Dai, Q. 2013b. Stimulation of phenolic metabolism by silicon contributes to rice resistance to sheath blight. J. Plant Nutr. Soil Sci. 176, 118-124.

Zhang, C., Wang, L., Nie, Q., Zhang, W., Zhang, F. 2008. Long-term effects of exogenous silicon on cadmium translocation and toxicity in rice (Oryza sativa L.). Environ. Exp. Bot. 62, 300-307.

Zhang, C., Wang, L., Zhang, W., Zhang, F. 2013a. Do lignification and silicification of the cell wall precede silicon deposition in the silica cell of the rice (Oryza 
sativa L.) leaf epidermis? Plant Soil 372, 137-149.

Zhou, L., Li, H., Cheng, F.Q., Shi, Y.L., Zhang, Q.H., Shi, W.Y. 2012 Co-remediation of cadmium-polluted soil using stainless steel slag and ammonium humate. Environ. Sci. Poll. Res. 19, 2842-2848.

Zhao, X.Q., Mitani, N., Yamaji, N., Shen, R.F., Ma, J.F. 2010. Involvement of silicon influx transporter OsNIP2;1 in selenite uptake in rice. Plant Physiol. 153, 18711877.

Zhu, N.W. 2007. Effect of low initial C/N ratio on aerobic composting of swine manure with rice straw. Biores. Technol. 98, 9-13.

Legends to Figures

Figure 1. The paddy soil system silicon cycle.

Figure 3. Schematic model of silicon interactions with arsenic and cadmium (and iron) from the soil solid phase through to leaf epidermal cells.

Figure 3. The benefits of silicon in rice culture in addition to increased yield through enhanced structural integrity and biomass. 


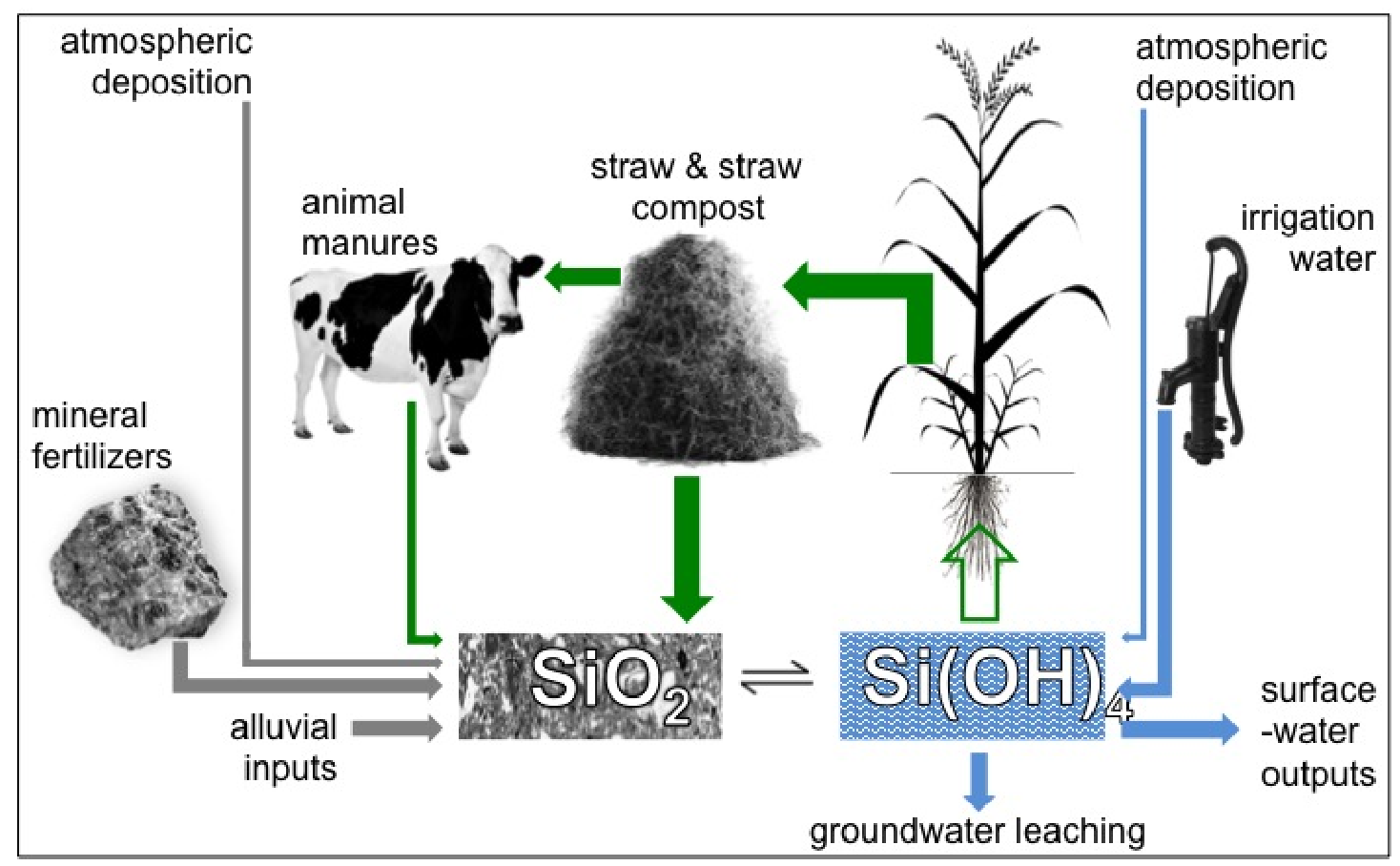

Fig 1 . 


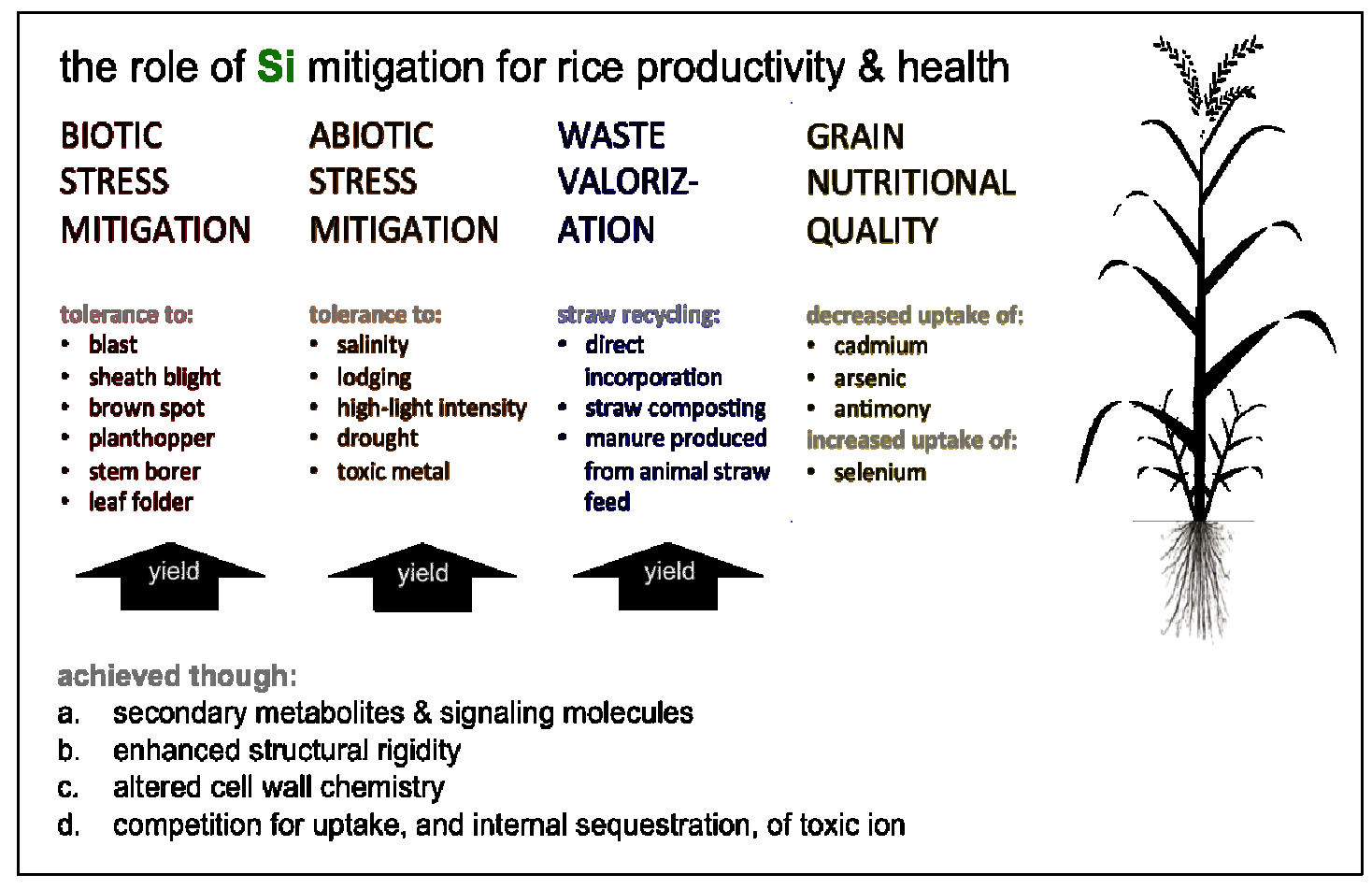

Fig 3 . 